\title{
Effects of air supply operation on the distribution and spatial differences of airflow field in conditioned room: A CFD Study
}

\author{
Yin Zheng, Guiqiang Wang*, Zhiqiang Kang, Xin Liu, and Zhixin Li \\ School of Municipal And Environmental Engineering, Shenyang Jianzhu University, Shenyang, \\ China 110168
}

\begin{abstract}
In air-blast freezer, there are differences in food freezing process at different locations due to the non-uniform airflow distribution in freezing chamber. In this paper, a decoupling method was used to simulate freezing process of food products at different locations. Firstly, the internal airflow distribution model of the freezing chamber was established to simulate the airflow field in freezing chamber under different velocities of air supply. The mainstream air flow rate around each food product was then calculated as the ambient air velocity at which the food freezes. Then, a validated lumped parameter model was used to simulate the freezing process of individual food product, and the effects of freezing conditions on freezing process at different locations were studied. The results showed that there were large differences in the freezing conditions of foods at different locations in freezing chamber, which were mainly reflected by the difference in ambient air velocity. Compared to air velocity, air temperature was distributed rather uniformly in freezing chamber. With the increase of supply air velocity of air coolers, the ambient air velocity around food products in freezing chamber increased almost linearly.
\end{abstract}

\section{Introduction}

In freezing chamber of cold storage, the forced convection is usually used to freeze the food. For specific food parameters such as food type, shape, size and packaging, the freezing process mainly depends on the airflow distribution around food product, including air temperature, velocity and turbulence. However, for large freezing chamber where large amount of foods are frozen simultaneously, the freezing conditions of foods at different locations cannot be the same due to the arrangement of food products, resulting in differences in the freezing process and freezing quality of food products at different locations.

Due to the high cost and difficulty of food freezing experiments, most of the researches on food freezing process are based on numerical methods, in which CFD(computational Fluid Dynamics) method is used most widely[1-5]. The decoupling method is usually employed for the heat and mass transfer process simulation[6-9]. The complex heat and

\footnotetext{
*Corresponding author:.wgq_hit@126.com
} 
mass transfer process between food and air is decomposed into three parts: the simulation of the external air parameters of food product, the calculation of the heat transfer coefficient at food surface, and the simulation of the heat and mass transfer process inside food product. For the large freezing chamber with amount of foods, the airflow field distribution is more complicated and hard to predict accurately. Most of the existing researches focus on the simulation of the internal flow field in freezing chamber, further research on freezing process at different locations is necessary to optimize the operation of refrigeration system[10-11].

This paper applied the theory of decoupling method in the simulation of food freezing process, and simulated the food freezing process in the freezing chamber in a step-by-step manner. Firstly, the internal airflow field distribution in the freezing room was simulated to calculate the air parameters around each food product as the freezing condition. Then the convective heat transfer coefficient was fitted into a dimensionless correlation. Finally, a validated lumped model for food freezing was employed to simulate the freezing process of food products at different locations.

\section{Model}

Simulating the external airflow field and the heat and mass transfer inside food product simultaneously can be time-consuming. The premise of a stepwise approach in this paper is that the convective heat transfer coefficient between food and air remains constant during the freezing process. The forced convection heat transfer coefficient mainly depends on the air parameters around the food, including air velocity and turbulence intensity. If the effect of the buoyancy force is taken into consideration, the natural convection will affect the flow field and thus the convective heat transfer coefficient. So that the convective heat transfer coefficient cannot be kept constant during freezing process. However, studies have shown that when the air velocity around food exceeds $0.5 \mathrm{~m} / \mathrm{s}$, the influence of natural convection on the convective heat transfer coefficient is negligible. Therefore in this research the natural convection was not considered as the air velocity around food generally exceeds $0.5 \mathrm{~m} / \mathrm{s}$ in air-blast freezer.

\subsection{Simulation of distribution of food freezing conditions in frozen rooms}

In this paper, the structure of the air-blast freezing chamber taken as the research object is shown in figure 1 . The geometric size is $19 \mathrm{~m} \times 6 \mathrm{~m} \times 4 \mathrm{~m}$. Six air coolers are installed on the ceiling of the freezing room.

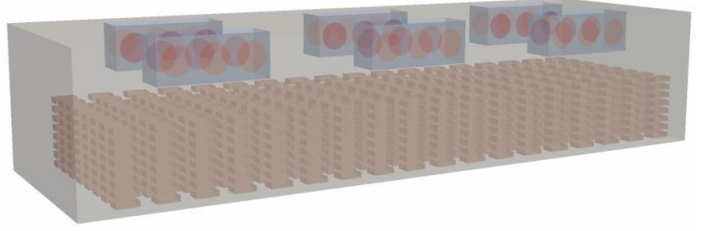

Fig. 1. The geometry and placement of food products in freezer.

The food products were placed on the shelves in freezing chamber. The geometry of individual food product is $0.6 \mathrm{~m} \times 0.4 \mathrm{~m} \times 0.15 \mathrm{~m}$, and the spacing between adjacent foods is $0.4 \mathrm{mx} 0.3 \mathrm{mx} 0.1 \mathrm{~m}$. The total number of frozen foods is 1152 . In order to reduce the moisture loss during the freezing process, the food products were covered with polyethylene film. Due to the barrier effect of the packaging material, the moisture transfer between food and air was neglected in modeling. In addition, the existence of the shelves has a certain impact on the internal airflow field, but studies have shown that ignoring the 
shelves has little effect on the accuracy of the flow field simulation. Therefore, the shelves were not considered in the simulation in this research. The following general differential equations were used to describe the air parameter distribution in the warehouse:

$$
\frac{\partial(\rho \phi)}{\partial t}=\nabla(\rho \phi \vec{v})=\nabla(\Gamma \nabla \phi)+S
$$

In the above formula, the transientand convection items are at the left side, and the diffusion item and source items are at the right side, respectively. In the airflow distribution simulation of freezing chamber, $k-\varepsilon$ model was selected as the turbulence model to simulate the mainstream. In order to calculate the heat release of the food accurately, a reinforced wall function was used and mesh refinement was performed in the near-wall area of food surface at air side. Boundary condition of air velocity was set to velocity inlet with a constant velocity,and supply air temperature and turbulence are set to $-10^{\circ} \mathrm{C}$ and $30 \%$ respectively. By adjusting the supply air velocity of air coolers, multiple simulations were carried out to study the effect of the flow rate of air coolers on food freezing process. The outlet of the air coolers was set to the free outflow boundary condition, and the wall surface of air coolers and storage enclosure applied the first type of boundary condition. As air supply velocity increased from $4 \mathrm{~m} / \mathrm{s}$ to $18 \mathrm{~m} / \mathrm{s}$, a total of 15 simulations were performed. In the simulated airflow distribution, parameters such as air temperature and velocity around each food product were calculated as the freezing conditions for individual food product.

\subsection{Fitting of convective heat transfer coefficient of food}

For the convective heat transfer coefficient of the food freezing process, a large number of convective heat transfer coefficient correlations have been obtained on the basis of experimental research, which can be directly used to calculate the convective heat transfer coefficient between food and air. However these correlations are usually restricted to application condition. For specific geometries and flow field in industrial process, it is often impossible to find a suitable convective heat transfer coefficient correlation. In this paper, the convective heat transfer coefficient between food and air was calculated by simulating the heat transfer process between food and air. By extracting the heat flow $q_{\text {conv }}$ and temperature difference $T_{\mathrm{s}}-T_{\mathrm{a}}$ between food surface and air from the airflow field, the convective heat transfer coefficient $h_{\mathrm{a}}$ was obtained based on Newton's law of cooling:

$$
h_{a}=\frac{q_{\text {conv }}}{T_{S}-T_{\mathrm{a}}}
$$

Theoretically, the convective heat transfer coefficient for each food product can be calculated from the flow field simulation of the warehouse, but this method is computationally intensive and cumbersome. In this work, an independent air duct model was used to simulate the convective heat transfer coefficient of food under different air parameters by changing the air velocity and turbulence intensity. The air velocity ranged from $0.5 \mathrm{~m} / \mathrm{s}$ to $5 \mathrm{~m} / \mathrm{s}$, and the turbulent intensity ranged from $10 \%$ to $60 \%$. According to the ranges of air velocity and turbulence intensity, a total of 60 simulations were performed, and the obtained convective heat transfer coefficient data were fit into dimensionless correlation as follows[9]:

$$
N_{u}=C \operatorname{Re}^{m} \operatorname{Pr}^{1 / 3} T u^{A}
$$

where, $N u, R e$, and $P r$ are the Nusselt number, Reynolds number, and Prandtl number of the flow field, respectively; $T u$ is the turbulence intensity, defined as the ratio of the root mean square of the pulsating flow rate to the corresponding mean flow rate, which is a characteristic value reflecting the strength of turbulence; The coefficients $C, m$, and $A$ were obtained by fitting the convective heat transfer coefficient. 


\subsection{Simulation of the freezing process of individual food}

Based on the simulation on freezing conditions of the food product and the calculation of the correlation coefficient of the convective heat transfer coefficient, the freezing process of the food itself was simulated. Lovatt's lumped parameter model was employed to simulate temperature changes during food freezing[12-13]. The model divides the freezing process into three stages of pre-cooling, phase change and super-cooling. The distance $x_{\mathrm{f}}$ of the ice peak from the thermal center was used to simulate the moisture phase change inside the food. In the pre-cooling phase, the following formula was used for calculation:

$$
V \frac{\mathrm{d} H}{d t}=\frac{E}{3} \frac{V \beta_{1}^{2} k_{1}}{X^{2}}\left(T_{a}-T_{m}\right)
$$

The simulation of phase change stage was performed by the following formula:

$$
\begin{gathered}
\frac{d x_{f}}{d t}=\frac{\mathrm{d} H}{d t}=L \frac{d x f}{d t} \frac{d V}{d x f} \\
L x_{f}^{n}\left[\frac{1}{h_{a} X^{N}}-\frac{T_{a}-T_{m}}{\left.k_{s}^{1-n}-X^{1-N}\right)}\right] \\
\frac{d V}{d x_{f}}=N\left(\frac{x_{f}}{X}\right)^{N-1} \frac{V}{X}
\end{gathered}
$$

where, $V$ is the volume of the food, $\mathrm{m}^{3} ; H$ is the volumetric devaluation of the food, $\mathrm{J} / \mathrm{m}^{3} ; k_{1}$ is the thermal conductivity of the food before freezing, $\mathrm{W} /(\mathrm{m} \bullet \mathrm{K}) ; k_{\mathrm{s}}$ is the thermal conductivity after food freezing, $\mathrm{W} /(\mathrm{m} \bullet \mathrm{K}) ; T_{\mathrm{m}}$ is the food center temperature, ${ }^{\circ} \mathrm{C} ; X$ is the characteristic length of the food, $\mathrm{m} ; E$ is the equivalent heat transfer dimension; $L$ is the phase change latent heat of food, $\mathrm{J} / \mathrm{m}^{3}$; The calculation method of food devaluation and parameters such as parameters $n, N, \beta_{1}$ in the equation can be found in the literature ${ }^{[12]}$.

The method of calculating the sub-cooling stage of the food is the same as that of the pre-cooling stage, and the post-freezing thermal conductivity $k_{\mathrm{s}}$ of the food is used instead of $k_{1}$.

In the simulation, the switching of the freezing stage was determined by comparing the freezing loads at different stages. When the freezing was at the pre-cooling stage, the food pre-cooling load and the phase-change load were compared, and when the freezing was in the phase change phase, the food phase-change load and the super-cooling load were compared. When the load in the next stage was greater than the load in the current stage of the food, the freezing switched to the next stage.

\section{Experimental validation}

In order to verify the airflow model in freezing chamber and the mathematical model of the food freezing process, a food freezing experiment was carried out in a small warehouse. The structure and food placement of the warehouse are shown in figure 2.

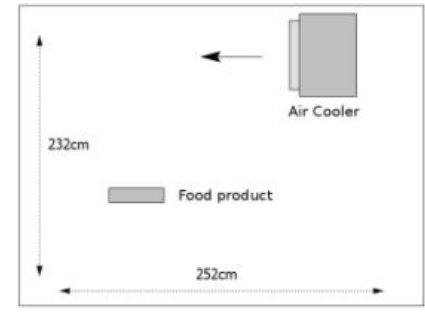

Fig. 2. The geometry of experimental freezer. 
The geometrical dimensions of the warehouse are $4.05 \mathrm{~m} \times 2.52 \mathrm{~m} \times 2.32 \mathrm{~m}$, the air temperature was controlled by "on/off" strategy. The air temperature fluctuated between the upper and lower limits. The temperature and humidity in warehouse were recorded by temperature and humidity recorders and input into the food freezing model. The food was frozen by forced air circulation driven by air coolers. The air cooler fans kept running during the freezing process. The diameter of the fan outlet is $0.53 \mathrm{~m}$ and hot wire anemometers were used to measure the air velocity. The frozen food products in the warehouse were covered with polyethylene film and packaged into carton and iron box. The food products were placed on the axial plane of the air cooler vent, and the temperature at the food center during the freezing process was recorded using a thermocouple.

Using the mathematical model proposed in this paper, the convective heat transfer coefficients between the packaged food and the carton packaged food and air were calculated to be $11.34 \mathrm{~W} /\left(\mathrm{m}^{2} \bullet \mathrm{K}\right)$ and $22.12 \mathrm{~W} /\left(\mathrm{m}^{2} \bullet \mathrm{K}\right)$, respectively. Comparing the simulated food center temperature with the measured results, as shown in figure 3 , it can be seen that the simulation results are in good agreement with the measured results, and the mathematical model can be used to further study the spatial difference of food freezing in freezing chamber.

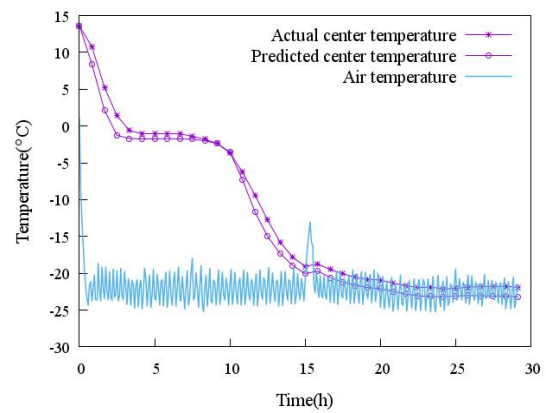

Fig. 3. Temperature profiles during freezing process.

\section{Discussion and results}

Based on the CFD simulation of the airflow field, the distribution of the airflow field in the warehouse was obtained, and the freezing conditions of the individual foods at different locations were calculated to analyze the spatial difference of food freezing. As the outlet air velocity of air coolers maintained at $10 \mathrm{~m} / \mathrm{s}$, the air velocity distribution of the bottom food in the warehouse on the horizontal plane is shown in figure 4. As can be seen from the figure, the air velocity in the area below air coolers is larger. As the cold air penetrates from the upper layer of food products to the lower layer, air velocity decreases rapidly. The airflow rate is small in the area near the inner wall of the enclosure. It can be seen that there is a large spatial difference in the air parameters in the warehouse, which will lead to differences in the freezing conditions of the food at different locations in the warehouse.

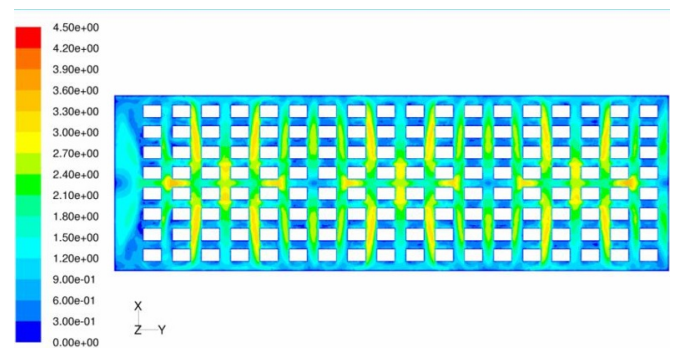

Fig. 4. Velocity magnitude $(\mathrm{m} / \mathrm{s})$ on the bottom plane. 
In the results of the airflow field distribution in the warehouse, the average value of the mainstream air parameters around each food product was calculated as the freezing condition for each product food. Figure 5 shows the air velocity distribution of the bottom food in freezing chamber. It can be seen that for the bottom food in the warehouse, the foods in different areas have different freezing conditions. Since air coolers were arranged along the length direction in the warehouse, the air velocity around food products is large in the area near to the outlet of air coolers, and three annular regions with large air velocity are formed at the central region.

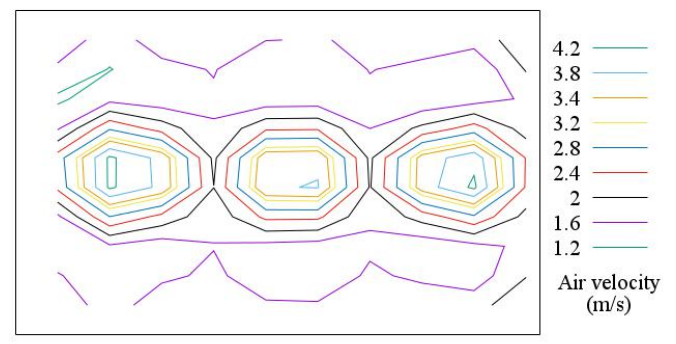

Fig. 5. Air velocity around each food product on bottom plane.

In actual operation, it usually takes a certain amount of time to put food products in storage. It is necessary to maintain a low temperature environment in the warehouse as the food products entering the warehouse. In this way, the food storaging early will be frozen for a while longer than the food storaging later in the warehouse, and eventually the food storaging early will complete the freezing process earlier. In order to make up for the difference in the freezing process caused by this, the food entering the warehouse early can be placed in the area where the air velocity is small.

As the supply air velocity of air coolers maintained at $10 \mathrm{~m} / \mathrm{s}$, the quantity distribution of the air velocity around food products in the warehouse is shown in figure 6 . It can be seen that the distribution of air velocity around food is similar to the normal distribution, the amount of food in the middle area is the largest in the overall air velocity range, and the quantity of food in the two ends is small.

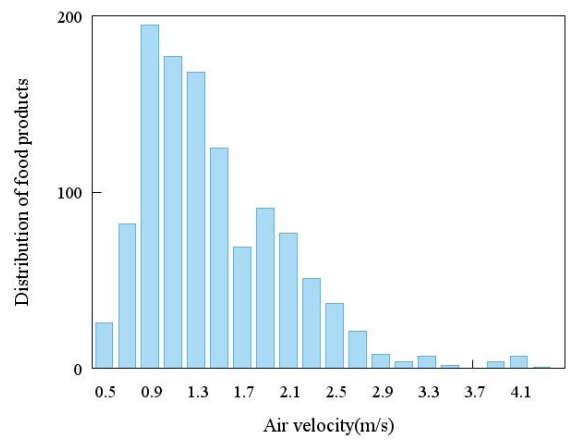

Fig. 6. Distribution of surrounding air velocity of food products.

On the basis of the simulation of airflow in freezing chamber, the air supply velocity of air coolers $(4 \mathrm{~m} / \mathrm{s} \sim 15 \mathrm{~m} / \mathrm{s})$ was further changed and simulated several times to study the difference of food freezing conditions under different supply air velocity of air coolers. Figure 7 shows the change of the air velocity around food when the speed of air cooler fans increases. It can be seen from the figure that the maximum, minimum and average air velocity around food increase linearly with the increase of the supply air velocity of air coolers. 


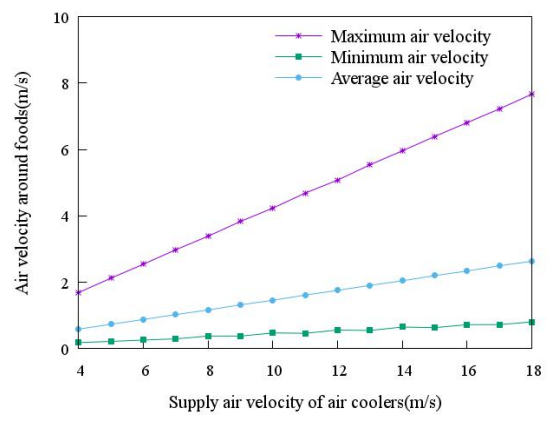

Fig. 7. Effects of supply air velocity of air cooler on freezing condition of food products.

The surface heat transfer coefficient calculation and freezing process simulation of individual food were combined to study the effect of supply air velocity of air coolers on food freezing process. The air temperature in the warehouse was kept unchanged at $-30{ }^{\circ} \mathrm{C}$. Freezing time is defined as food temperature drops from the initial temperature of $10{ }^{\circ} \mathrm{C}$ to $-15{ }^{\circ} \mathrm{C}$. Figure 8 shows the change in freezing time required for foods under different freezing conditions when the supply air velocity of air coolers increases. It can be seen that as the supply air velocity of air coolers increases, the freezing time of the food is gradually reduced, and this trend tends to be flat with the further increase of the supply air velocity of air coolers. With the increase of the supply air velocity of air coolers, the reduction of the freezing time of the food under the minimum air velocity in the warehouse is the largest, from $60.87 \mathrm{~h}$ to $42.61 \mathrm{~h}$. The reduction of the freezing time of the food under the maximum air velocity is small, only $6.67 \mathrm{~h}$. Combined with the trend of air velocity around each food, it can be seen that for the food products under lower air velocity, the freezing time of the food can be obviously shortened by raising air velocity around them. For the food products under high air velocity, the effect of raising air velocity is not obvious.

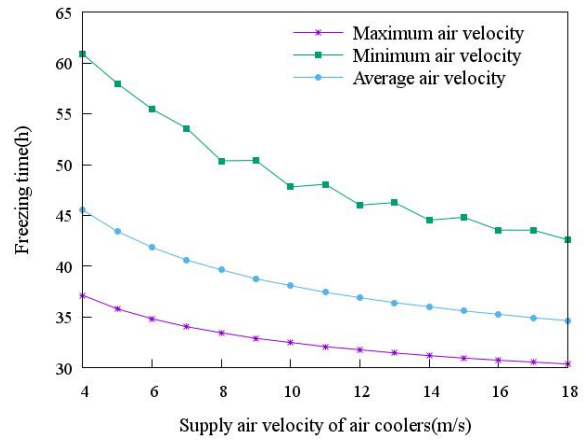

Fig. 8. Effects of supply air velocity of air cooler on freezing time of food products.

\section{Conclusion}

The airflow field in freezing chamber is not uniform due to various factors such as the installation position of air coolers, the placement of the food, and the enclosure structure. The non-uniform distribution of airflow field usually results in different freezing conditions of food products at different locations, which leads to the difference in freezing process of food products. In order to make up for the difference in freezing time of the food due to the difference in spatial position, the food products entering the warehouse at early stage should be placed in the area with poor freezing conditions, and the foods entering at later stage should be placed in the area with better freezing conditions. By changing the supply air velocity of air coolers in airflow simulation and combining the simulation on the 
freezing process of individual food, it can be seen that the air velocity around food products increases with the increase of the supply air velocity of air coolers. The freezing time required for the food is reduced with the increase of supply air velocity of air coolers. This decreasing trend is especially obvious when the air velocity around food products is small.

\section{Acknowledgments}

The authors wish to acknowledge the support of the Program of National Science and Technology of China during the Thirteenth Five-year Plan (grant No.2017YFB060400403)and the National Natural Science Foundation of China (No.51508341) for this work.

\section{References}

1. Kolodziejczyk M, Smierciew K, Gagan J and Butrymowicz D 2016 Numerical Modelling of Heat and Mass Transfer in Vegetables Cold Storage Procedia Eng. 157 279-84

2. Parpas D, Amaris C, Sun J, Tsamos K M and Tassou S A 2017 Numerical study of air temperature distribution and refrigeration systems coupling for chilled food processing facilities Energy Procedia 123 156-63

3. Laguerre O, Duret S, Hoang H M, Guillier L and Flick D 2015 Simplified heat transfer modeling in a cold room filled with food products J. Food Eng. 149 78-86

4. Defraeye T, Lambrecht R, Delele M A, Tsige A A, Opara U L, Cronjé P, Verboven P and Nicolai B 2014 Forced-convective cooling of citrus fruit: cooling conditions and energy consumption in relation to package design J. Food Eng. 121 118-127

5. Defraeye T, Verboven P and Nicolai B 2013 CFD modelling of flow and scalar exchange of spherical food products: Turbulence and boundary-layer modelling $J$. Food Eng. 114 495-504

6. Trujillo F J and Pham Q T 2006 A computational fluid dynamic model of the heat and moisture transfer during beef chilling Int. J. Refrig. 29 998-1009

7. Sun D-W and Hu Z 2002 CFD predicting the effects of various parameters on core temperature and weight loss profiles of cooked meat during vacuum cooling Comput. Electron. Agric. 34 111-27

8. $\quad \mathrm{Hu} \mathrm{Z}$ and Sun D-W 2000 CFD simulation of heat and moisture transfer for predicting cooling rate and weight loss of cooked ham during air-blast chilling process J. Food Eng. 46 189-97

9. Pham Q T, Trujillo F J and McPhail N 2009 Finite element model for beef chilling using CFD-generated heat transfer coefficients Int. J. Refrig. 32 102-13

10. Mirade P-S, Kondjoyan A and Daudin J-D 2002 Three-dimensional CFD calculations for designing large food chillers Comput. Electron. Agric. 34 67-88

11. Nahor H B, Hoang M L, Verboven P, Baelmans M and Nicolaï B M 2005 CFD model of the airflow, heat and mass transfer in cool stores Int. J. Refrig. 28 368-80

12. Lovatt S J, Pham Q T, Cleland A C and Loeffen M P F 1993 A new method of predicting the time-variability of product heat load during food cooling - Part 1: Theoretical considerations J. Food Eng. 18 13-36

13. Lovatt S J, Pham Q T, Loeffen M P F and Cleland A C 1993 A new method of predicting the time-variability of product heat load during food cooling - Part 2: Experimental testing J. Food Eng. 18 37-62 